\title{
Individual differences and associational strategies within whole-list, mastery paired-associate learning
}

\author{
WILLIAM M. TIMPSON \\ Colorado State University, Fort Collins, Colorado 80523 \\ and \\ ROBERT E. DAVIDSON and FRANK H. FARLEY \\ University of Wisconsin, Madison, Wisconsin 53706
}

\begin{abstract}
Learning efficiency was studied as a function of instructed learning strategies and individual differences in anxiety and achievement motivation. Within a self-paced whole-list design, college subjects learned to mastery a paired-associate list under one of three experimental conditions: rote repetition, mediation, and an uninstructed control. Although mediation proved superior to rote repetition, both techniques were inferior to the control. Anxiety was positively correlated with performance under rote repetition. No relationships emerged for achievement motivation. The evidence suggests that the learning styles of college students may be too sophisticated to be improved by any one learning technique and that the interrelationships of personality variables and individual learning styles may be difficult to extract.
\end{abstract}

In a study of paired-associate (PA) learning within a whole-list study design, it was found that mediational strategies were superior to rote repetition (Timpson \& Davidson, Note 1). In the present study an attempt was made to expand on this general paradigm in two ways: (1) to include an uninstructed learning control group where the subjects were given no specific learning techniques to employ and (2) to incorporate personality measures of anxiety and achievement motivation into the analysis.

Subject's recall of PA lists has been shown to be facilitated by the use of mediators (e.g., mnemonic devices, natural language mediators, imagery) that elaborate on or create associations between the word pairs as presented (Davidson, 1964; McNulty, 1966; Montagu, Adams, \& Kiess, 1966; Rundquist \& Farley, 1964; Spiker, 1960). Jensen and Rohwer (1963), however, were unable to find this effect among high school and college students, suggesting that students mediate spontaneously by that age. In the present study, as in its precursor (Timpson \& Davidson, Note 1), mediation was expected to be supeior to rote repetition. The performance of the uninstructed learning control was predicted to fall between these two condtions.

An important feature of the present study and that of Timpson and Davidson (Note 1) was the attempt to incorporate features into the experimental procedure that would more closely approximate the learning situations students face in school. Although, admittedly, some degree of experimental control was sacrificed, the greater generalizability that these studies appeared to offer to actual school learning situations seemed to be sufficient compensation. First, group testing rather than individual testing was employed; the study list was presented as a whole and was subject-paced rather than experimentally controlled and experimenter-paced, as in most PA learning designs. Second, for the group receiving mediation instructions, differing techniques were illustrated for differing imagery-level values of the noun pairs. In any given situation each subject decided upon the most appropriate technique (i.e., imaginal associations for high-imagery or easy pairs, verbal elaborations for low-imagery or more difficult pairs, or combinations thereof for pairs of moderate difficulty). Training and practice opportunities were not provided.

With respect to anxiety, Spence, Farber, and McFann (1956) reported an interaction between drive level, or manifest anxiety, and performance at easy and complex PA and serial tasks. High-drive subjects outperformed those low in manifest anxiety on easy tasks, but the relationship was inverted on difficult tasks. It was expected that within the present study this relationship would hold for the relatively easy technique of rote repetition vs. the more complex and difficult mediational techniques. The Taylor Manifest Anxiety Scale (1953) was employed as a measure of anxiety.

With respect to achievement motivation, a positive correlation was expected between need to achieve and performance within each treatment group. McClelland, Atkinson, Clark, and Lowell (1953) found a significant increase in recall of incompleted-interrupted tasks for subjects high in achievement motivation as a function of 
expectation of performance evaluation. The Farley Drive Scale (1968), a very direct eight-question index of achievement motivation, was employed.

\section{METHOD}

A total of 63 undergraduates were assigned equally to one of the three experimental conditions: rote repetition, mediation, and an uninstructed learning control. The PA list was composed of high-, medium-, and low-imagery noun pairs. The entire PA list appeared on the study page, but only the stimulus words appeared on the test page, with spaces provided for the subject to write the response words. The performance criterion was mastery and the dependent variable was time to mastery, with each subject allowed a maximum of three study-test trials.

\section{RESULTS AND DISCUSSION}

The uninstructed learning control group (mean time to mastery $=14.67 \mathrm{~min}$ ) outperformed the mediation group (mean $=16.22 \mathrm{~min}$ ), which, as expected, outperformed the rote-repetition group (mean $=19.94 \mathrm{~min}$ ). The one-way analysis of variance between groups was significant $(F=3.69, \mathrm{df}=2 / 60, \mathrm{p}<.05)$, although no individual pairwise comparison reached the $95 \%$ confidence level.

For those under rote-repetition instructions, there was a significant negative relationship $(r=-.49, \mathrm{df}=21$, $\mathrm{p}<.05)$ between total time to mastery and anxiety.

Across groups, achievement motivation and anxiety were negatively correlated $(r=-.25, \mathrm{df}=63, \mathrm{p}<.05)$. Grade-point average and achievement motivation were positively correlated $(\mathrm{r}=.24, \mathrm{df}=63, \mathrm{p}<.05)$.

Beyond the finding that mediation can improve performance over rote repetition, it was also shown that the uninstructed learning control was superior to both. From this evidence and posttest questioning, it is obvious that the learning sets and styles of students are quite complex by the time they reach college, incorporating many modes of association.

As predicted, more anxious subjects were apparently better able to utilize the relatively simple technique of rote repetition. Contrary to prediction, however, the performance of low-anxiety subjects was not superior for complex mediational techniques.

Achievement motivation was not significantly correlated with time to mastery within any group, although its significant positive relationship with grade-point average lends support to the use of the Farley Drive Scale in the study of academic achievement.

The learning sets and styles of students may be so sophisticated by the time they reach college that any one technique serves only to depress optimal performance, unless the technique is well practiced and functional to that subject's learning style. Personality variables as a whole, though assuredly at play in learning situations, may be too complex in their interrelationships with learning techniques and styles to be easily extracted and utilized for diagnosis and application to learning situations.

\section{REFERENCE NOTE}

1. Timpson, W. M.. \& Davidson, R. E. Mediation and study strategies under self-paced study conditions in pairedassociate learning. Unpublished manuscript. University of Wisconsin, 1973.

\section{REFERENCES}

Davidson, R. E. Mediation and ability in paired-associate learning. Journal of Educational Psychology, 1964, 55. 352-356.

Farley, F. H. Predicting physical persistence from an unsubtle measure of "drive." Journal of General Psychology, $1968,79,279-282$.

Jensen, A. R., \& Rohwer, W. D., JR. Verbal mediation in paired-associate learning. Journal of Verbal Learning and Verbal Behavior, 1963, 5, 25-27.

McClelland, D. C., Atkinson, J. W., Clark, R. A.. \& Lowell, E. L. The achievement motive. New York: Appleton-Century-Crofts, 1953.

McNulty, J. A. The effects of "instructions to mediate" upon paired-associate learning. Psychonomic Science, 1966, 4, 61-62.

Montagu, W. E., Adams, J. A., \& Kiess, H. O. Forgetting and natural language mediation. Journal of Experimental Psychology, 1966, 72, 829-933.

Rundouist, W. N., \& Farley, F. H. The use of mediators in the learning of verbal paired-associates. Journal of Verbal Learning and Verbal Behavior, 1964, 3, 280-285.

Spence, K. W., Farber, I. E., \& McFann, H. H. The relation of anxiety (drive) level to performance in competitional and non-competitional paired-associate learning. Journal of Experimental Psychology, 1956, 52, 296-305.

SpIKer, C. C. Associative transfer in verbal paired-associate learning. Child Development, 1960, 31, 73-87.

TAYLOR, J. A. A personality scale of manifest anxiety. Journal of Abnormal and Social Psychology, 1953, 48, 285-290.

(Received for publication February 24, 1978.) 